\title{
Neoextractivismo en la mineria, prácticas coloniales y lugares de resistencia en Amazonia, Brasil
}

\author{
Edna Ramos de Castro* \\ UNIVERSIDADE FEDERAL DO PARÁ / CNPQ.
}

\section{RESUMEN}

Este artículo busca reflexionar, bajo una perspectiva crítica y postcolonial, sobre las dinámicas de las transformaciones sociales, económicas, étnicas y políticas, en contextos vinculados a los procesos intensivos de explotación mineral neoextractivista y el avance del capital financeiro sobre nuevos territórios. Las masivas inversiones públicas y privadas en obras de infraestructura, en Brasil, están, todos ellas, vinculadas a los intereses de expansión del capital para nuevas áreas - mineral, forestal, de energía y del agronegocio - todas ellas productoras de commodities para el mercado mundial. En síntesis, se procura demostrar el papel del Estado y de sus políticas en los procesos de cambio, y toma como referencia analítica las investigaciones realizadas por largos ańos en la región amazónica brasileña, y en la fronteira pan-amazónica que atraviesa nueve países de América del Sul. En el plano empírico, este artículo considera el análisis y los estudios sobre los desastres socio-étnico-territoriales ocurridos en regiones con explotación neoextractivista y sobre los grandes emprendimientos de infraestructura construidos para viabilizarlos, a ejemplo de las plantas hidroeléctricas, de transporte y portuarias.

Palabras claves: Neoextrativisme. Mineria. Transformaciones territoriales. Conflictos. Amazônia. Brasil

\section{Abstract}

This article aims to reflect, in a critical and post-colonial perspective, on the dynamics of social, economic, ethnical and political changes under processes bound to intensive processes of mineral exploration with neo-extrativist character, and the advance of capital over new territories. All large public and private investments in infrastructure works in Brazil are linked to interests on expansion of capital for new areas- mining, forestry, electric power and agro business. - all of them producers of commodities for the world market. In conclusion, this work tries to demonstrate the role of the State and its policies in the processes of change, and its policies and uses as analytical reference research done for many years in the Amazon, and in the Pan-Amazon frontier that crosses several South American countries. In the empirical plan, this article considers the analysis and studies on socio-ethnical- territorial disasters occurred in the region with the neo-extrativist exploration and the large infra-structure ventures built in the region, such as hydroelectric power plants, transport and ports.

Key words: Neo-extrativism. Mining, Territorial transformations. Conflicts. Amazon, Brazil.

*edna.mrcastro@gmail.com 


\section{INTRODUCCIÓN}

ste artículo busca reflexionar sobre las dinámicas de las transformaciones territoriales (sociales, económicas y políticas) en contextos vinculados a los procesos intensivos de explotación mineral con carácter neo-extractivista (GUDYNAS, ACOSTA, 2011). En trabajo anterior analizamos los proyectos de infraestructura propuestos tanto por los Planes de Aceleración de la Economía (PAC I y II), como por las inversiones promovidas por la Iniciativa de Integración Regional del Sur de América (IIRSA) en varios países suramericanos en la frontera con Brasil, observando las transformaciones en sus territorios (CASTRO, 2012a; 2012b). Las masivas inversiones públicas y privadas en obras de infraestructura están, todos ellas, vinculadas a los intereses de expansión del capital para nuevas áreas - mineral, forestal, de energía y del agronegocio - todas ellas productoras de commodities para el mercado mundial.

Se observa un avance del capital sobre nuevos territorios. Se trata de cambios provocados por la globalización en el papel del Estado y en la formulación de sus políticas. Un nuevo modelo de gestión de la esfera pública se ha colocado como materia esencial, reforzando la necesidad de repensar el Estado. Pero también el modelo que ha permeado la producción de las sociedades latinoamericanas, excluyentes y desiguales. Los acontecimientos políticos más recientes, el desencanto con el desarrollo y las recurrentes catástrofes ambientales, han contribuido para la construcción de un pensamiento crítico que ha mostrado la necesidad de repactar estado y sociedad, economía y política, en el sentido de procesos democráticos y de participación, tensionadas otras alternativas de desarrollo.

En síntesis, se procura demostrar el papel del Estado y de sus políticas en los procesos de cambio, y toma como referencia analítica las investigaciones realizadas por largos años en la región amazónica que atraviesa varios países de América del Sur. En el plano empírico, este artículo considera el análisis y los estudios sobre los desastres socio-étnico-territoriales ocurridos en regiones con explotación neoextractivista y sobre los grandes emprendimientos de infraestructura construidos para viabilizarlos, a ejemplo de las plantas hidroeléctri- 
cas, de transporte y portuarias. Barcarena, Estado de Pará, Brasil, un espacio altamente transformado por la implantación de grandes emprendimientos de minería y siderurgia desde la década de 1970 y, más recientemente, por la expansión portuaria para viabilizar el corredor de exportación del agronegocio y de otras actividades del entorno, viene sufriendo seguidos desastres ambientales ${ }^{1}$ de grandes magnitudes. Los impactos provocados sobre la población local - urbana y ribereña - revelan el aumento de la violencia y la destitución de derechos, contrarios a los discursos de desarrollo regional y progreso producidos por las “áreas” de planeación del Estado y señalado también en páginas electrónicas y algunos emprendimientos.

\section{1.- Desarrollo y nuevos territorios del Capital}

La problemática del desarrollo ocupó lugar relevante en el conjunto de la reflexión de las ciencias sociales y económicas en América Latina, sobre todo a partir de mediados del siglo XX. Perspectivas y orientaciones teóricas bien diversas alimentaron los debates enfocados al entendimiento, por un lado, de los procesos históricos y de la dinámica del capitalismo, como los estudios sobre industrialización y agricultura, dependencia y subdesarrollo, estructura de la propiedad y formación del Estado-nación, urbanización, división social del trabajo, alienación y dominación, marginalidad e ideologías; y, por otro, se destacaron las cuestiones relacionadas a las acciones del Estado, la planificación, las políticas de crecimiento económico y las estrategias de industrialización y de exportación. Y, aún, las discusiones sobre la eficacia simbólica de las instituciones y de las agencias mundiales con sus discursos sobre la planeación del desarrollo.

Esos estudios componen un considerable inventario sobre las sociedades latinoamericanas, comprendiendo la brasileña, con contribuciones y abordajes venidos de tradiciones teóricas diferentes y de varias disciplinas, conformando un campo intelectual de intenso debate en la intersección entre lo político, lo social y lo académico. Probablemente, este siempre fue un tema central en la construcción del pensamiento crítico latinoamericano.

En los días actuales se observa la emergencia de nuevas cuestio- 
nes puestas al conocimiento y a los paradigmas con los cuales las ciencias sociales y económicas procuraron entender e interpretar la sociedad. Sean sociales, económicas, políticas, ambientales, o interrelacionadas, transversalizadas, ellas desafían el entendimiento de prácticas y procesos, como aquellos referidos al desarrollo. En esa perspectiva entendemos la relevancia de una revisión paradigmática rigurosa al respecto de temáticas dejadas al margen en los análisis del desarrollo, como las referencias al lugar (ESCOBAR, 2003; 2005; RIST, 2001) y a la descolonización del conocimiento (RAMOS, 1996; QUIJANO, 2005; MIGNOLO, 2008; RIVERA, 2010; SANTOS, 2009) que se tornan, en nuestra visión, temas prioritarios en la reflexión. Pero ¿qué teorías tendrían la fuerza de romper con las generalizaciones político ideológicas presentes en las interpretaciones del desarrollo que son marcadas por la perspectiva evolucionista, clasificadora y jerarquizadora? ¿Cómo entender los fundamentos de la racionalidad que estuvieron en la base de la legitimación de discursos y prácticas clasificatorias de países en el sistema mundial (de desarrollados a subdesarrollados, de ricos a pobres)? Esas y otras preguntas ya fomentaron debates en el pasado como la crítica a la razón formulada por Francisco de Oliveira (2003) y aún con contribuciones fundamentales de Fernandes (1965), Ianni (1971) y Ramos (1996) referidas al reduccionismo epistemológico presente en las interpretaciones sobre la sociedad y la economía brasileñas.

Un balance de la trayectoria del debate intelectual y político sobre desarrollo, aunque parcial, nos ayudaría a identificar los sentidos subyacentes a las ideologías y utopías que predominaron en el siglo XX, y, todavía, narrativas, conceptos y sentidos producidos en el juego de relaciones entre agentes. Llamo la atención para abordajes contemporáneos provenientes sobre todo de la tradición del pensamiento crítico latinoamericano, formulado en el ámbito de la ciencia, tales como la sociología, la antropología, la geografía, por los movimientos insurgentes, por las teorías feministas, por la ecología política y por los estudios poscoloniales y subalternos. Esos abordajes han procurado romper con los paradigmas dominantes de las interpretaciones sobre el desarrollo formulados en creencias, 
tales como, en el evolucionismo, en el proceso civilizatorio occidental, en los sistemas clasificatorios y en las posibilidades de crecimiento económico por etapas. Al formular la crítica a la modernidad, al colonialismo, al racismo y al evolucionismo, entendemos el ejercicio epistemológico de rupturas con matrices estructurantes, de desmontar mitos y creencias sobre el desarrollo, aun presentes y hegemónicas en la representación de las sociedades contemporáneas sobre sí mismas. Esto porque los valores de la modernidad y de la racionalidad cartesiana todavía atraviesan la sociedad y actualizan, con eficacia simbólica, las relaciones de poder y de dominación, la desigualdad social y la supresión de derechos, toda vez que los discursos, en cuanto práctica, sobre el desarrollo, como recuerda Ribeiro (2008), son esencialmente discursos políticos.

Las políticas desarrollistas de los gobiernos latinoamericanos, progresistas o conservadores, junto a los intereses económicos sobre los recursos naturales, han llevado, en las últimas décadas, a potencializar el avance sobre las fronteras nacionales, como se verifica en el caso de la explotación de minerales, sea en la triple frontera de Brasil, Perú y Colombia, sea entre Brasil y Venezuela, Brasil y Bolivia o, aún, entre Brasil y Guyana Francesa. Los espacios transfronterizos se tornan nuevas áreas de expansión de mercado y tienden a tornarse más accesibles en función de la logística de transportes que aproxima las fronteras, así las estrategias de los estados nacionales oscilen entre procesos de integración y defensa de intereses nacionales.

En el sector extractivo mineral la circulación de productos, o sea materias primas, constituye un área importante debido al volumen a ser transportado por distancias enormes, por las vías ferroviaria y marítima, con capacidad de atender flujos diferenciados de materias primas y productos semi industrializados, garantizando la circulación mundial y regional de esos bienes. Para abordar las transformaciones globales a través de la circulación de productos y mercancías, se deben analizar las dinámicas portuarias y las cadenas productivas globales. A partir de 2007, el Estado brasileño viene ejecutando la política de infraestructura (logística) destinada a atender los ejes del PAC de transporte y energía, y una nueva estrategia nacional enfo- 
cada en la logística de transportes (terrestre, ferroviario, marítimofluvial y portuario), justificando la necesidad de superar el llamado costo-Brasil, minimizando las restricciones de los beneficios de competitividad y eficiencia brasileńa en el mercado globalizado.

La coyuntura brasileńa evidencia las transformaciones ocurridas en la sociedad y en la economía en las últimas décadas, entre ellas la diferenciación interna del uso del suelo y de la estructura de la propiedad. Efectivamente, los territorios fueron transformados por las conexiones más intensas de lo local en el mercado global justamente por la exportación de commodities minerales y agrícolas. En esa perspectiva, al investigar los efectos de los circuitos económicos de algunos sectores clave, tales como las cadenas productivas, sobre todo de la pecuaria, de la madera, de los granos y de los minerales, se observa que el control de esos flujos puede parcialmente ocurrir en Brasil, aunque sus dinámicas están sobre todo en países de Europa, a donde la mayor parte del hierro, principal producto mineral de exportación de Brasil es llevado y reexportado, de Asia y Estados Unidos.

Esos flujos de productos e informaciones circulan en nivel global y ocurren muchas veces fuera de la zona de influencia y hasta de la comprensión de los agentes nacionales. Eso nos pone ante la necesidad de entender cómo esas nuevas fuerzas sociales, políticas y económicas reconstruyen sus estrategias de dominación, gobernanza y control sobre los territorios que ellos invaden, según la narrativa de los antiguos ocupantes, con sus emprendimientos.

2.- Neoextractivismo y ecología política: una mirada SObRe EL BRASIL

Las dinámicas recientes en Brasil, desde las últimas décadas del siglo XX, muestran la paradoja de una legislación ambiental avanzada, la aprobación de dispositivos legales e institucionales, pero cuyo desafío principal de mantener la selva en pie se torna imposible por el avance de la frontera del capital selva adentro, acompañado de fuerte desreglamentación, sea por la vía legal de cambio en los dispositivos, sea por su no cumplimiento, por tanto, trasladando al Estado para 
la ilegalidad. La paradoja también del reconocimiento de derechos a la tierra como bien común, de pueblos indígenas y quilombolas, al tiempo que financia el avance rápido de la pecuaria, de las plantaciones de soja y palma de aceite, y de los mega emprendimientos, en dirección a esos territorios. Tales problemas y violaciones conforman la cartografía de los conflictos sociales, étnicos y ambientales en el encuentro de esos frentes.

La historia económica de América Latina y de Brasil se inscribe en la explotación intensiva de recursos naturales. A lo largo del tiempo sus economías, vista en las pautas del comercio exterior, fueron sustentadas por la extracción de recursos para exportación, y cuanto más ricos en recursos del suelo y subsuelo, mayores los intereses en juego, como apunta Acosta (2016) que considera el extractivismo como una modalidade de acumulación que comenzó a ser forjada en grande escala há quinientos años, y entiende que la economía mundial - el sistema capitalista - se estructuró encima de la conquista y colonización de las Américas, de África y de Asia.

$Y$, al final, ¿qué distingue el extractivismo del neoextractivismo? Para Acosta (2016) el término extractivismo es usado para designar las actividades que remueven grandes volúmenes de recursos naturales no procesados y que se destinan sobre todo a la exportación. Procesos que hoy se desarrollan con tecnologías avanzadas y alto poder de intervención en el territorio. El tiempo es otro. Ciertamente no es el del reloj. Los avances tecnológicos permitieron imprimir extraordinaria rapidez en el desmonte y transporte del mineral de su lugar de origen para otro, justificando el uso del término neoextractivismo como elemento de distinción de patrones diferentes, así se trate del mismo proceso. En ese sentido construye una narrativa e integra procesos naturales y sociales en la misma construcción conceptual, en la perspectiva crítica de la ecología política. Y todavía, se caracteriza y se distingue también por el tamaño de los impactos producidos sobre los territorios, por los riesgos permanentes y los desastres sociales y ambientales producidos. Gudynas (2010) señala la persistencia del neoextractivismo sea en la gestión de gobiernos progresistas o conservadores, en América Latina, como un pilar de 
desarrollo, pues "para além da propriedade dos recursos, reproduzemse as regras e of funcionamento dos processos produtivos voltados para a competitividade, a eficiência, a maximizaçāo da renda e a externalização de impactos", considerando que ese término apunta para la inserción internacional subordinada y funcional al mercado del capitalismo transnacional (GUDYNAS, 2010) marcado por el mito del progreso y del desarrollo, actualizando un imaginario contemporáneo y la cultura política.

Los procesos de colonización de las Américas agenciaron mecanismos de saqueo y apropiación de riquezas como práctica corriente. Eso ocurrió en todos los países de las Américas, resaltando las diferencias que tenían que ver, entre otros, con los tipos de recursos abundantes. Las prácticas extractivistas atraviesan los siglos y llegan al presente, pero ahora con el uso de tecnologías de explotación más eficaces, y contando con mano de obra especializada para responder a las demandas de productividad y competitividad, ante procesos flexibles que posibilitan mayor reproducción del capital. La base del extractivismo es todavía la producción de materias primas y, como muestran los estudios sobre la dependencia en América Latina ${ }^{2}$, sirvieron a las dinámicas de acumulación en el desarrollo industrial de países del Norte global, reproduciendo la división internacional del trabajo y las prácticas coloniales, no tomando en cuenta " $a$ sustentabilidade dos projetos extrativistas ou o esgotamento dos recursos. Soma-se ainda o fato de que a maior parte da produçáo das empresas extrativistas não se destina ao consumo no mercado interno, mas sim à exportação" (ACOSTA, 2016).

Imposible no asociar, en la historia latinoamericana, la producción de materias primas que es el ítem principal en su pauta de exportación, y de la dependencia política y económica que mantiene los salarios bajos, el desempleo, la desigualdad y la pobreza, comparativamente a los países industrializados. Una sociedad cuya práctica económica dominante gira en torno de la extracción de recursos naturales, sin internalizar el procesamiento industrial, molda necesariamente un imaginario de poder "rentista", considerando las tensiones en torno a la cuestión fundiaria. El poder de mando 
configurado en prácticas clientelistas, patrimonialistas y esclavistas. Los países exportadores se especializaron en materias primas, dependientes de demandas de fuera y que, a lo largo del tiempo, sufrieron oscilaciones de precios y también la tendencia a la deterioración de los términos del intercambio (SALAMA, 2016a).

La minería es una actividad invasiva y conflictiva como mostra la historia de las economías latinoamericanas basadas en el petróleo y la minería, como actividades extractivistas, sem promovem os encadeamentos dinâmicos tão necessários para se alcançar um desenvolvimento coerente da economia, como reflete Acosta (2006), aunque reconozca que coexista, en esos países, sistemas diferentes, sea con alta productividad, sea con baja productividad.

El uso del vocablo neoextractivismo por autores ya referidos como Svampa (2017) procura alertar sobre viejas cuestiones que permanecen actuales, pues se refieren a escogencias políticas llevadas a cabo tanto por gobiernos conservadores como por progresistas, en un encuentro con el mercado, pudiendo ser empresas muy modernas, con tecnología sofisticada y además innovadora de procesos y de gestión, aun cuando trabajan con procedimientos simples de extracción de materia prima y de exportación en grandes convoyes ferroviarios ${ }^{3}$ o navíos mineros, para el mercado mundial. Países muy ricos en recursos naturales, pueden obtener grandes sumas de rentas financieras, aumentar el Producto Interno Bruto, mas no conseguir las bases necesarias para la reducción de la desigualdad, pues esta implica romper con la dinámica de acumulación del capital y de concentración de la tierra y de las riquezas. Opción política que ha conducido a resultados negativos como a marginalización de otras formas de creación de valor y de distribución de renta. El pensamiento crítico en América Latina, al realizar estudios sobre los procesos neoextractivistas y los debates junto con los movimientos sociales y étnicos, ha formulado otra perspectiva de desarrollo que reconoce la multiplicidad de saberes y epistemes, la acción colectiva como proceso emancipatorio, posibilitando la ampliación de la noción de bienes comunes. Una de esas perspectivas, al interrogar la universidad del saber (occidental) y su hegemonía, propone el 
concepto del Bien Vivir como dimensión crítica de la reflexión sobre un posdesarrollo.

3.- LOS SEÑORES DE HIERRO: AUTORITARISMO DE LOS EMPRENDIMIENTOS Y DOMINACIÓN COLONIAL

Las relaciones autoritarias en América Latina hicieron su curso a lo largo de siglos de colonización europea. Aunque se hayan producido rupturas con los movimientos insurgentes de independencia y de abolición de la esclavitud, pilares críticos de las relaciones entre metrópolis y sus colonias, esas rupturas no fueron suficientemente profundas para dar origen a sociedades donde el poder de mando, las oligarquías, el patrimonialismo y el paternalismo no pudiesen reproducirse en las mismas dimensiones anteriores ${ }^{4}$.

Sin pretender extenderme en la formación social y económica de América Latina, países con trayectorias comunes y al mismo tiempo tan diversos, consideramos importante profundizar los estudios sobre el pensamiento crítico latinoamericano, sobre la historia de las ideas en un continente cuyas narrativas producidas por los grupos dominantes han procurado silenciar los movimientos insurgentes y la libertad de pensar fuera de los cánones de saberes reconocidos, como una "desobediencia epistemológica", assinalado por Mignolo (2008). La sociología política, la historia social y la ecología política han compartido el debate sobre América Latina y abierto caminos de reflexión a partir de los conflictos, de las luchas de trabajadores y de los movimientos sociales y étnicos, y en el reconocimiento de sentido de la crítica política.

Es importante elaborar un pensamiento crítico sobre la dinámica de mercado, comprender el papel de las grandes corporaciones y de los gobiernos en la construcción de políticas aplicadas al desarrollo. Comprender, por otro lado, las experiencias cotidianas de actores sociales y étnicos, de trabajadores y estudiantes, de mujeres y hombres, y cómo esas vivencias territorializadas consiguen formular un entendimiento de lo que es nuestra América.

Pero el pensamiento crítico latinoamericano enfrenta problemas, al desarrollar y ampliar una narrativa crítica para el mundo que cam- 
bia muy rápidamente y que altera las formas de existir de pueblos, sus derechos, sus modos de vida. Los impactos de los modelos de desarrollo pueden ser irreversibles, como los cambios climáticos y la subida de la violencia institucionalizada en el mundo, y que exige cada vez más personas conscientes y dispuestas a tomar decisiones en términos colectivos, como acciones colectivas. Debate que nos concierne a todos y exige una revisión de los paradigmas de la percepción, de los principios de la ciudadanía y de la democracia.

Las narrativas sobre los procesos de cambio en nuestras sociedades han repasado categorías clave como desarrollo, territorio, emancipación y movimientos sociales - y también temas que tienen que ver con democracia, extensión de los derechos humanos y el entendimiento seminal de la naturaleza como sujeto de derecho. En fin, el desarrollo continúa siendo una categoría central de análisis político.

El año 2000, nos leva a evocar la guerra de agua que hubo en Cochabamba, Bolivia, pois marca un momento de inflexión de luchas sociales en América latina. Contra una gran empresa del sector agua se dieron levantamientos y movimientos de protesta que repercutieron en toda Latinoamérica, Brasil, Argentina, Ecuador, Perú y Colombia. Son luchas que se colocan en la agenda política. Nuevas institucionalidades, emergencia de gobiernos más populares, que se denominaban progresistas, pudiendo decirse que neste inicio de siglo el continente entraba en una fase de autodeterminación y construcción, esperavase, de un modelo emancipatorio, descolonizado, mais autentico com a cultura latinoamericana. En sintiese que refletisse la trayectoria del pensamiento crítico en la economía política. Emergiram, ciertamente, ideas relacionadas al desarrollo, como sustentabilidad, concepto de bien vivir, bien común, derecho de la naturaleza y que tienen que ver con las luchas territoriales de agentes sociales de categorías muy diversas y multiculturales.

En el momento fundacional de Ecuador y de Bolivia aparecen nuevas constituciones - derechos de carácter colectivo son institucionalizados, eso permite hablar en frontera de los derechos - derechos colectivos, derechos territoriales que parecen ser incorporados en las constituciones, con los actores movilizados. Ninguna consti- 
tución del mundo incorporó la idea de naturaleza como sujeto de derechos. Estamos ante la posibilidad de romper las fronteras del derecho, de los derechos humanos y de la naturaleza, de los derechos individuales y colectivos, del sentido olvidado por muchos, pero no perdido en el tiempo, el de los comunes, los bienes comunes, de romper las conformaciones de las identidades de género y étnicas. Muchos cambios importantes, pero no fueran suficientes para que los governos progressistas impusessem um nuevo modelo de desarrollo democrático y se vuelta a la tormenta de los governos conservadores y autoritarios.

4 - ¿DesarRollo para QuiÉN? ¡VIeja CUestión QUe CABE aún PREGUNTAR!

Desde la mitad del siglo XX el tema del desarrollo ha tenido un lugar central en los campos intelectual, político y económico, como una de las principales matrices conceptuales e ideológicas sobre América Latina. El desarrollo como gran narrativa. Narrativa, en síntesis, sobre la transformación del capitalismo en los últimos siglos, sobre todo con el aumento de la velocidad en los procesos productivos a partir de la Revolución Industrial. Para Castells (1999) los cambios del final del siglo XX trajeron la emergencia de la sociedad informacional y la conformación de las relaciones sociales en red $\mathrm{y}$, por eso, alterando, en el sistema mundial, el lugar del conocimiento y su funcionalidad en la sociedad, junto con las prácticas sociales.

Sin embargo, la visión del desarrollo no es única, así la narrativa dominante sea aquella que sustenta el crecimiento económico. De este modo, se puede relacionar, de forma simplificada, las siguientes perspectivas: 1 - liberal y neoliberal, por considerar las estrategias y las políticas enfocadas a los estímulos del mercado; 2 - de la crítica al desarrollo como proceso político asociada a la crítica de la modernidad (ADORNO, 2005; HABERMAS, 1989; LIPOVESKY, 2009; BAUMAN, 2006; ARAUJO, 2013)5. Los movimientos sociales proponen una visión del desarrollo que no esté centrada en una visión economicista y sí de valorización de la vida, de la cultura, de la naturaleza ${ }^{6}$ - eso supone pensar en territorio diferente, con 
otros sentidos simbólicos. Esa visión se diversifica en varias líneas de interpretación y ha sido objeto de una reflexión más fecunda de la sociedad; 3 - de la crítica poscolonial y decolonial, en cuanto formulaciones más radicales del punto de vista de la crítica teórica sobre la historia colonial y sus procesos de racialización. Esta ha partido de intelectuales y de movimientos sociales que piensan el desarrollo en contravía del pensamiento dominante, al reflexionar sobre la diversidad social, étnica, de saberes presentes en países del Sur y de la ecología política. Este artículo procura entender, a partir de esta última perspectiva teórica, la dinámica del neoextractivismo y de sus impactos sociales y ambientales, en la Amazonia brasileña.

Los argumentos fueron formulados a partir de pesquisas sobre la experiencia social y movilizaciones de diferentes segmentos de la sociedad. Se observa ese debate, de un lado, entre líderes de movimientos y de organizaciones sociales, enfocadas en la relación territorio y cultura, y, de otro, entre intelectuales que reinterpretan el entendimiento del mundo, más allá de la esfera política de la dominación occidental.

Se encuentra en la reflexión sobre el poscolonialismo la importante relectura de autores que formularon el debate en el campo del desarrollo, en los ańos 1950 y siguientes, y que dieron contribución seminal al pensamiento latinoamericano ${ }^{7}$. Los estudios sobre los mitos coloniales a propósito de la naturaleza y de los pueblos originarios y las representaciones sobre la ética civilizatoria atravesaron los siglos y aún constituyen una clave del entendimiento de las sociedades latinoamericanas actuales y de los sueños que movilizaron agentes y acciones (GONDIM, 2007; CASTRO, 2010), y legitimaron, en el orden occidental, el exterminio de pueblos y culturas. Gilbert Rist (2001) discurre sobre la función social de las creencias y trata el desarrollo como un sistema de creencias orgánicamente relacionado a la expansión mundial de sistemas de mercados integrados.

Siguiendo la tradición marxista, estimada en las ciencias sociales, existen varias corrientes que proyectan sus miradas en la revisión epistemológica y en los efectos que pueden traer para las intervenciones en el campo del desarrollo. Entre las diversas tendencias presentes en 
el debate se encuentra el ecosocialismo que entiende los problemas ambientales resultantes de la organización social, del modo de producción capitalista y de las formas de alienación, apropiación de la naturaleza y explotación de la fuerza de trabajo (LÖVY, 2010). Otra interpretación perfilada en el pensamiento marxista, y sobre todo en el diálogo interdisciplinar y transversal a las diversas tradiciones teóricas, es la ecología política que orienta sus teorizaciones en la relación sociedad x política x naturaleza. Formula su crítica a la maximización del lucro y a la mercantilización de la naturaleza, y por eso, observa Leff (2003), produce un discurso sobre la desnaturalización de la naturaleza: de las condiciones naturales de existencia, de los desastres "naturales", de la "ecologización de las relaciones sociales" a una economía sustentable. Considera que no se trata de adoptar una 'perspectiva constructivista de la naturaleza, sino política, donde las relaciones entre seres humanos y entre ellos y la naturaleza se construye a través de relaciones de poder (LEFF, 2003).

La ecología de saberes se basa en la idea de que el conocimiento es interconocimiento. $Y$ en el reconocimiento de la pluralidad de conocimientos heterogéneos y en interacciones dinámicas entre ellos sin comprometer su autonomía. Esa percepción del lugar de lo político en el debate sobre el campo del desarrollo cuestiona la creencia sobre la sustentabilidad de una economía insustentable. Para Leff (2003) la ecología política se encuentra en un campo teórico-práctico, el cual busca construir un nuevo territorio del pensamiento crítico y de la acción política.

Aunque ciertamente la lógica dominante permanece siendo la del mercado y se orienta a la aceleración del crecimiento económico ${ }^{8}$. Lo que predomina en este momento en Brasil son las políticas de incentivo a la exportación de materias primas para el mercado mundial, de commodiities, lo que significa procesos neoextractivistas y una creciente primarización de la economía (SALAMA, 2016b), y no considera la crítica hecha a la visión productivista de uso privado de los territorios con recursos minerales? 
5.- Minería y prácticas neoextractivistas en Brasil

La producción mundial de hierro se triplicó a partir de 2005, según DPMN, y Brasil acompańó ese crecimiento, con gran participación del hierro de Carajás, aun cuando a tasas menores a partir de 2012. A pesar de la caída de precios en el mercado mundial, esa pérdida fue compensada por la intensificación de la extracción del mineral, atendiendo demandas de parques industriales siderúrgicos como China, Japón y Estados Unidos. La mayor planta de hierro de la Vale S.A. se encuentra en el Estado de Pará, en la región de Carajás, en el complejo mina-ferrovía-puerto (centenas de vagones forman cada uno de los convoyes que salen de la mina, en el municipio de Parauapebas, en el Pará, hasta el Puerto de Itaqui, en São Luis, Maranhão). El valor exportado por la Amazonia corresponde al del $40 \%$ del país, destacando el aluminio, hierro y acero, que representaron más de $70 \%$ del valor exportado en 2006 . Pero, menos de $2 \%$ de los empleos formales de la región vienen de la minería. La Provincia Minera, en Pará, responde por 26\% del PIB del Estado, teniendo el mineral de hierro como principal producto (75\% en 2014). En el Mapa! a seguir se puede ver que la ocurrencia de minerales esta en todo el pais.

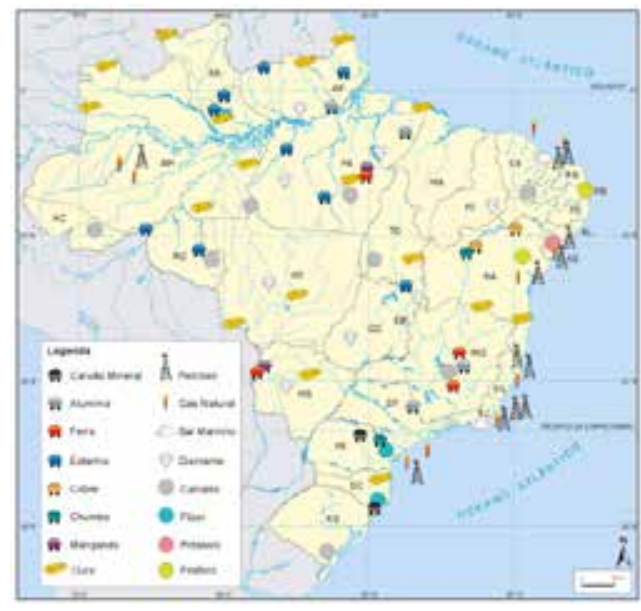

Figura 1 - Ocurrencia de minerales en en territorio brasileño www.educabras.com/media/emtudo_img/upload/_img/20140218_123719.gif 
La explotación mineral en Brasil se caracteriza por la ocupación de nuevas zonas de frontera minera. Procesos que alteran el uso de la tierra con desplazamientos forzados de poblaciones en el campo y también en pequeńas ciudades. Los grandes emprendimientos se incrustan en los territorios ya ocupados, aunque funcionan con lógica y prácticas privadas. Tienen el poder de influenciar la formulación y la aprobación de dispositivos legales que favorezcan sus intereses sobre el territorio. Procedimientos ilegales para minimizar los costos ambientales hacen parte de prácticas adoptadas por empresas con sede en la Amazonia, donde se ha observado varios tipos de impactos sobre las comunidades locales: 1 - los conflictos sociales, étnicos y ambientales; 2 - la desestructuración de la economía familiar; 3 - restricciones impuestas a diferentes formas de trabajo de poblaciones en regiones como la Amazonia, y observadas igualmente en la Patagonia chilena, en los Andes colombianos y en regiones amazónicas con selva tropical de varios países suramericanos; 4 -reducción del empleo en las canteras de obras; 5 - desaparecimiento de recursos naturales esenciales en la construcción de los instrumentos de trabajo; 6 - pérdida de biodiversidad y de recursos utilizados en el sistema de salud tradicional.

A la precarización del trabajo, medida por los indicadores de renta, hoy se junta otra forma de precarización venida de la destrucción de los lugares de trabajo, como expresaron los caciques de los pueblos indígenas afectados por la construcción de la hidroeléctrica de Belo Monte. $\mathrm{O}$ en el discurso de Alesandra Munduruku, profesora cuya aldea se encuentra en la margen derecha del río Tapajós asediada entre puertos recién construidos en frente de la ciudad de Itaituba, en Audiencia en el Congreso Nacional, el 24 de mayo de 2018: "inserir a fala dela em portugues"

La imposibilidad de trabajar es consecuencia de las transformaciones en la naturaleza, con el aumento de la deforestación, la pérdida de la biodiversidad, la contaminación de cursos de agua y del aire. Las investigaciones han mostrado que el entendimiento de un megaproyecto de minería encierra una compleja operación para identificar las escalas de actuación de los emprendimientos y 
las contradicciones implícitas en la relación con las comunidades y los poderes locales. Cabe, ciertamente, el análisis de la relación de esos emprendimientos con el campo político, pues, como mostraron los escándalos de la relación conspicua de grandes empresas con el Estado brasileño, en todos los niveles de la acción política gubernamental (federal, estatal y municipal), el juego de sustentación en las dinámicas de mercado globalizado, depende también de apropiación privada del funcionamiento del Estado, su captura, vía sobornos y favores corruptos inaceptables en estados democráticos y republicanos.

Como sintetiza Svampa (2017), al hablar de la doble dinámica territorial, la dinámica del enclave y la dinámica del desplazamiento, que se va expandiendo con los intereses de crecimiento económico neoextractivista. Empuja las sociedades locales para una zona, la del sacrificio (ZHOURI; VALENÇO, 2014)). Se está frente a situaciones extremas, y en mundos separados, divididos, con relaciones de poder asimétricas. El mundo de la economía de enclave y el de la realidad social, económica y política de los lugares.

La producción minera brasileña tiene como productos principales el hierro, que corresponde a $13,89 \%$ de la producción mundial, seguida de la bauxita con 13,20\%. El Gráfico 1 muestra la relevancia de los valores exportados: entre febrero de 2009 y diciembre de 2015, Brasil exportó un total de US\$ 148.526.825.724,04, en valores de diciembre de 2015. Hubo aumento anual, y el total exportado de 235,8 toneladas en 2009 pasó a 315,0 toneladas en 2015. Conforme el Anuário da Mineração, el "preço médio de exportação variou bastante durante este periodo, partindo de 44,9 dólares por tonelada em 2009, crescendo rapidamente até atingir 115,9 dólares por tonelada em 2011. O preço declinaria, em menor medida, para 86,5 em 2012 e 92,1 em 2013; e, posteriormente, seguiu uma trajetória de queda, chegando ao menor valor da série em 2015 (32,9 dólares por tonelada, em média) ${ }^{10}$. "Siguiendo la misma fuente, hubo oscilaciones en el valor de las exportaciones de hierro en el período, ultrapasando los 33 billones de dólares en 2011 - precio medio practicado más elevado de la serie - siendo después el valor reducido para 19,9 bi- 
llones de dólares en 2014 y 10,3 billones en 2015.

Tabla I - Producción Minera bRasileña X MUNDo (20I3)

\begin{tabular}{|c|c|c|c|}
\hline \multicolumn{4}{|c|}{ PHODUÇÃO MINERAL BRASILEIRA X MUNDO (2013) } \\
\hline Produte & Mundo & Brasill & XErati-Muando \\
\hline Mreto at Fermo & 28500000 & 410000 & $12 \times 9$ \\
\hline$A \infty$ & 1.550 .050 & अ.178 & 2 mas \\
\hline lleuta & 259.000 & 342000 & $13.2 \mathrm{ss}$ \\
\hline Ataminio & 47300 & 1395 & $2.00 \times$ \\
\hline $\cos n$ & 17900 & 400 & $2,6 a x$ \\
\hline thos & 13500 & zकs & 2.10 \\
\hline Nove & 2496 & 149 & 5.958 \\
\hline Oune: & $2 m 0 \mathrm{t}$ & 751 & 206 \\
\hline 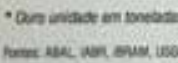 & & & mose peneser \\
\hline
\end{tabular}

El siguiente gráfico muestra el movimiento de las exportaciones de hierro de Brasil, de 2009 a 2015, producto mineral más importante en la pauta de exportación del país y que en gran parte es retirado de las minas de Carajás, en el Estado de Pará.

Erafico I - Brpotaçàede minerio de ferro. quantidade exportada fem mithces de toneladas) e preço

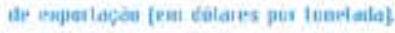

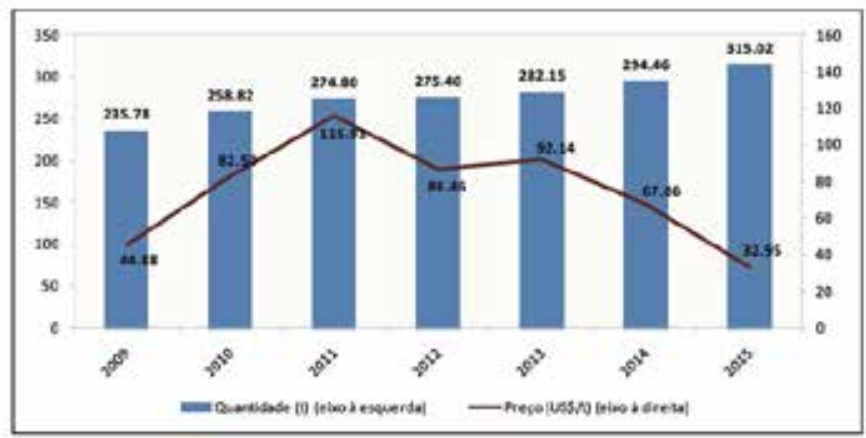

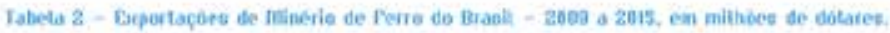

Brasil permanece con las mismas bases extractivistas, exportador de mineral bruto o casi bruto, sin valor agregado e innovación tecnológica. La producción de las empresas VALE y SAMARCO (esta última responsable por la mega avalancha de desechos industriales, 
en Mariana, Estado de Minas Gerais, en 2016) fue de 34,4 millones de toneladas al año, en 2014, crecimiento muy expresivo en relación con 2013 que fue de 30,7 millones de toneladas. La SAMARCO produjo 24,4 millones de toneladas en 2014, superior a las 22,2 millones de toneladas de 2013.

\section{6.- Minería en la Amazonia: políticas neoextractivistas de PRODUCCIÓN DE COMMODITIES}

Los ejemplos a ser narrados sobre la minería en la Amazonia, en los últimos 50 años, nos muestran el financiamiento de una dinámica de acumulación que se asienta sobre el avance de la frontera del extractivismo - el avance de dinámicas económicas sobre la selva, produciendo una tragedia traducida en la deforestación; el avance sobre tierras ocupadas por poblaciones tradicionales por parte de grandes empresas para fomentar el agronegocio, las plantaciones de eucalipto; la construcción de megaproyectos hidroeléctricos, con sus enormes represas que privatizan las aguas, la ocupación de tierras para construcción de carreteras y ferrovías, buscando atender la salida de granos y minerales y, finalmente, la construcción de puertos en la desembocadura de casi todos los grandes ríos tributarios del río Amazonas. Este momento implica una confrontación con los límites de la vida, de la sociedad y de la naturaleza, constituyendo lo que Zhoury (2016) llama de zonas de sacrificio - eso conforma un campo de procesos que residen en una concepción de poder sobre la naturaleza, en la práctica extractivista que, lejos de ser natural, es introducida en escala comercial a partir de la colonización de las Américas y de la transformación de bienes colectivos, de usos comunes, en bienes enajenables, privatizables ${ }^{11}$.

En el Estado de Pará, además de los grandes emprendimientos en funcionamiento, como los relativos al hierro, el oro, el cobre y el manganeso de Carajás, la bauxita del río Trombetas, el aluminio de Albras-Alunorte, y muchos otros emprendimientos en Canáa do Carajás y del río Capim, se implantaron nuevos, como en el municipio de Juriti, con una empresa estadounidense, Alcoa, que explota la bauxita, materia prima para la producción de aluminio. Otro 
emprendimiento de la Vale, en el sudeste de Pará, la explotación de cobre en el municipio Canaã dos Carajás, y diversos minerales en Sáo Félix do Xingu, Xinguara, Ourilândia do Norte, Barcarena, entre otros. La energía es esencial, sobre todo para las empresas electro intensivas, y en esos casos fueron construidas varias hidroeléctricas.

En el Estado vecino, Maranhão, se implantaron las empresas Suzano Celulose y Vale para realizar la duplicación de la Carretera Carajás, la construcción de la Ferrovía Norte Sur, bien como tienen intereses en la construcción de la hidroeléctrica de Estreito, en el municipio de Estreito al oeste del estado. Todos proyectos recientes, de alto poder de transformación de los territorios que envuelven los municipios de Barcarena, Marabá, Capim (Imerys Rio Capim, Pará Pigmentos a Rio Campi Caulim), Parauapebas, Canãa dos Carajás, São Luís, Açailândia, Santa Inês, etc. y a lo largo de la ferrovía, donde aún existen factorías de hierro de gusa. Igualmente, cambios acelerados se produjeron en las dos últimas décadas con la construcción de las hidroeléctricas de Belo Monte (río Xingu), de Jirau y Santo Antônio (río Madeira), de Marabá (río Tocantins) y los estudios para implantación de cinco hidroeléctricas en el río Tapajós, justamente una reconocida provincia minera, con existencia y explotación antigua de oro a través de minas ${ }^{12}$.

Se trata del avance de la lógica del capital, de la posesión privada de la tierra y de sus recursos, ignorando criminalmente sus formas corrientes de ocupación comunal y colectiva. Y el poder de las empresas y sus estrategias de coerción han llevado con frecuencia a desreglamentar los marcos legales, al interior del Estado, por una clase política y gobiernos descomprometidos con el sentido público de los bienes comunes. Son narrativas en disputa. Y eso queda muy evidente con las tensiones, los conflictos, las coacciones legales y el proceso autoritario en la aprobación de los emprendimientos. Lo que ha evidenciado, como en el caso de Belo Monte, que el desarrollo no se hace sin violencia, aun extrema, cuyos aparatos de un estado de excepción, en el sentido aplicado por Agamben (2004), noción que ha sido usada en el entendimiento de la modalidad de producción del golpe en la democracia brasileña en 2016, son evo- 
cados para imponer los intereses del sector minero. Eso evidencia la fragilidad de los dispositivos democráticos en Brasil.

En las siguientes tablas (Tablas 2 y 3) se observa que la producción mineral en el Estado de Pará se concentra en la producción de hierro, que tuvo un aumento de 2015 para 2016 de 14,1\%, de bauxita e de cobre, especialmente con las explotaciones de la Vale. Pero, relacionando los datos con los de la Tabla 2, se observa el aumento del volumen de producción, correspondiendo a intensificación de la extracción de hierro, con el aumento de 17,2\%, para compensar la disminución del valor de commodities minerales en el mercado internacional.

Tabla 2 - Producción Mineral Beneficiada en el Estado de PARÁ - 2OI 5 Y 2016

\begin{tabular}{|l|l|l|l|}
\hline Recurso mineral & 2015 & 2016 & $\Delta 15 / 16$ \\
\hline Agua mineral $^{1}$ & 228.708 .118 & 230.222 .989 & $0,7 \%$ \\
\hline Bauxita & 33.240 .415 & 32.450 .740 & $-2,4 \%$ \\
\hline Caliza & 1.276 .939 & 878.699 & $-31,2 \%$ \\
\hline Caolín & 1.424 .152 & 1.375 .785 & $-3,4 \%$ \\
\hline Cobre & 533.036 & 802.783 & $50,6 \%$ \\
\hline Hierro & 129.553 .878 & 147.833 .612 & $14,1 \%$ \\
\hline Manganeso & 1.966 .970 & 1.978 .851 & $0,6 \%$ \\
\hline Níquel & 83.551 & 55.099 & $-34,1 \%$ \\
\hline Oro $^{2}$ & 5.886 & 2.431 & $-58,7 \%$ \\
\hline
\end{tabular}

Fuente: Empresas/DDM/SUP-DNPM/PA, 2017

1. Unidad expresada en litros.

2. Unidad expresada en $\mathrm{kg}$. 
Tabla 3 - Volumen de la Comercialización de Recursos MineRales del Estado de Pará - 20 I 5 Y 2016

\begin{tabular}{|l|l|l|l|}
\hline \multirow{2}{*}{ Recurso mineral } & \multicolumn{3}{|c|}{ Volumen de comercialización $(\mathrm{t})$} \\
\cline { 2 - 4 } & 2015 & 2016 & $\Delta 15 / 16$ \\
\hline Bauxita & 33.263 .976 & 32.357 .377 & $-2,7 \%$ \\
\hline Caliza & 1.276 .939 & 878.699 & $-31,2 \%$ \\
\hline Caolín & 1.391 .689 & 1.461 .381 & $5,0 \%$ \\
\hline Cobre & 805.662 & 823.305 & $2,2 \%$ \\
\hline Hierro & 126.297 .784 & 147.985 .828 & $17,2 \%$ \\
\hline Manganeso & 1.617 .299 & 1.585 .440 & $-2,0 \%$ \\
\hline Níquel & 83.352 & 55.750 & $-33,1 \%$ \\
\hline
\end{tabular}

Fuente: Empresas/DDM/SUP-DNPM/PA, 2017

Las Tablas 4 y 5 muestran los movimientos de comercialización de recursos minerales en el Estado de Pará, permitiendo relacionar la exportación para el mercado interno y para el exterior. Aunque el hierro corresponda a $70 \%$ de la exportación para el mercado interno, el volumen es ínfimo, cerca de $2 \%$ del volumen comercializado va para el mercado externo. Hubo un aumento de 2015 para 2017 en los dos mercados. Se muestra, por tanto, una alta dependencia al mercado externo, y a sus variaciones de precios de commodities.

\begin{tabular}{|l|l|l|l|}
\hline \multirow{2}{*}{ Recurso mineral } & \multicolumn{3}{|c|}{ Volumen comercializado } \\
\cline { 2 - 4 } & \multicolumn{3}{|c|}{ Mercado Externo } \\
\cline { 2 - 4 } & 2015 & 2016 & $\Delta 15 / 16$ \\
\hline Bauxita & 9.144 .027 & 9.261 .383 & $1,3 \%$ \\
\hline Caolín & 1.047 .244 & 1.069 .503 & $2,1 \%$ \\
\hline Cobre & 797.924 & 823.306 & $3,2 \%$ \\
\hline Hierro & 124.363 .055 & 144.686 .031 & $16,3 \%$ \\
\hline Manganeso & 1.383 .744 & 1.395 .673 & $0,9 \%$ \\
\hline Níquel & 83.035 & 52.276 & $-37,0 \%$ \\
\hline
\end{tabular}

Fuente: Empresas/DDM/SUP-DNPM/PA, 2017 
Unidad: Tonelada

\begin{tabular}{|l|c|c|c|}
\hline \multirow{2}{*}{ Recurso mineral } & \multicolumn{3}{|c|}{ Volumen comercializado } \\
\cline { 2 - 4 } & 2015 & 2016 & $\Delta 15 / 16$ \\
\cline { 2 - 4 } & 24.199 .949 & 23.095 .994 & $-4,6 \%$ \\
\hline Bauxita & 344.445 & 391.879 & $13,8 \%$ \\
\hline Caolín & 7.738 & - & - \\
\hline Cobre & 1.934 .728 & 3.299 .797 & $70,6 \%$ \\
\hline Ferro & 233.554 & 185.768 & $-18,7 \%$ \\
\hline Manganeso & 317 & 3.475 & $996,2 \%$ \\
\hline Níquel & & \multicolumn{3}{|c|}{ Mercado Interno } \\
\hline
\end{tabular}

Fuente: Empresas/DDM/SUP-DNPM/PA, 2017

Considerando el liderazgo en el sector mineral de Pará de la bauxita, de la cadena de aluminio y de la producción de hierro, destacamos, a seguir, las grandes empresas/consorcios que ocupan las tres áreas principales de minería en Pará: 1 - Bauxita - Mineração Rio do Norte y Juruti; 2 - Aluminio - Producción de la Hydro; 3 - Hierro - Producción de la VALE. Sobre cada uno de esos casos apuntamos las condiciones de producción neoextractivistas y los impactos producidos en el territorio, sean efectos sobre los grupos sociales que allí se encontraban, o se instalaron más recientemente por los procesos migratorios intensos hacia esas regiones, y los efectos ambientales, calificando los desastres ocurridos.

6.1 Mineração Rio do Norte À Juruti: nuevas Áreas de exploTACIÓN DE BAUXITA

Sobre la bauxita, la primera gran empresa instalada en la Amazonia fue la Mineração Rio do Norte (MRN), en 1970 para explotación de bauxita en el río Trombetas, afluente del río Amazonas, el cual fue paralizado en el año de 1972. En esa época, la empresa atribuyó su paralización a problemas de financiamiento y a la retracción en el mercado de aluminio. Es con la crisis del petróleo que el proyecto vuelve a ser discutido a través de una propuesta de su "nacionalización” con la participación de la CVRD y de la Companhia Brasi- 
leira de Alumínio (CBA). En 1974, las dos pasan a ser las principales accionistas del grupo MRN. El proyecto inicia su operación en 1979, algunos ańos después del descubrimiento por la Alcan de los yacimientos de bauxita, en el margen izquierdo del río Amazonas, aun en la década de 1960. Se viabilizó, con la explotación de la bauxita, la transferencia de plantas industriales de aluminio de Japón para la Amazonia (CASTRO, ALONSO, NASCIMENTO, 2016). Las ocupaciones del territorio por grupos afroamericanos tienen registros que datan del siglo XIX, como muestran Acevedo y Castro (1992), en aquella región del Trombetas, situación ignorada totalmente por la empresa y sus estudios de viabilidad ${ }^{13}$.
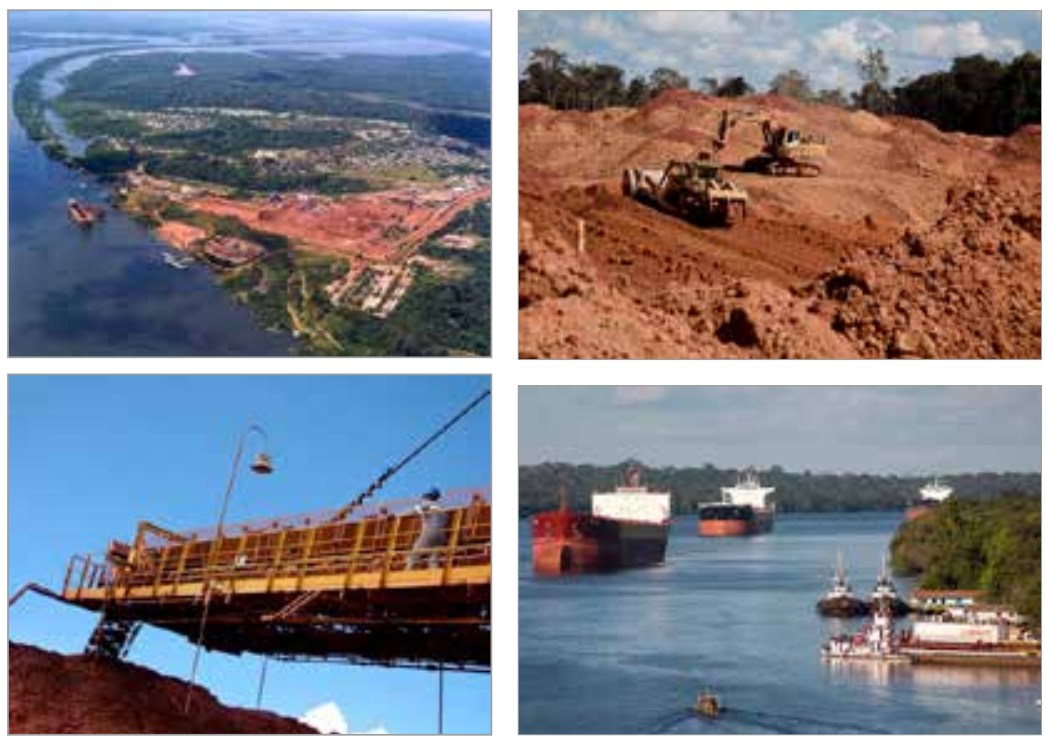

Neste momento, el Pará es el principal produtor brasileño de bauxita explorada en las minas localizadas en el Oeste del estado, en Oriximiná (44\% de la producción nacional), y Juruti (12\%). El Pará produce $85 \%$ y Minas Gerais 14\%. de la producción nacional, y posiciona el Brasil en tercero lugar de la producción de bauxita en el mondo (14,1\%), después de Austrália (30,45\%) y China (21\%).

La intensidad de la explotación de bauxita por la MRN que configura procesos neoextratrivistas, aumentó en el transcurso de los 
años. Según datos del Departamento Nacional de Produção Mineral (DNPM) de 2011, hay 94 procesos mineros en curso, siendo 21 de ellos sobre tierras afroamericanas en el mismo municipio de Oriximiná. De estos, 10 son referentes a la concesión de extracción de minerales. Los procesos se refieren a los siguientes minerales: bauxita (26 procesos), fosfato (33 procesos) y oro (35 procesos), segundo la Comissão Pró-Índio de São Paulo, em 2011. Las empresas con procesos de minería que se sobreponen a territorios afro en Oriximiná son: BHP Billiton Metais S.A.; Mineração Rio do Norte S.A.; Vale S.A.; Amazonas Exploração e Mineração Ltda.; RBS- Redstone Mineração do Brasil Ltda.; Pará Metais Nobres Ltda.; Brasmidia, Administração de Bens, Títulos e Valores Imobiliários; y Posto Novo Progresso Ltda. Pasados 37 años, parte significativa de las minas está agotada. Avanza sobre otras áreas de selva que son unidades de conservación, la Floresta Nacional Saracá-Taquera y la Reserva Biológica do Rio Trombetas, ya teniendo en funcionamiento, en aquella, la mina Saracá. La presión sobre los territorios afro tiende a agravarse

Figuras 2, 3 y 4 - Esteira de transporte de bauxita; exploración de la mina; navios mineros - Minería Rio do Norte/MRN, en Oriximiná, estado del Pará.

6.2 Producción de aluminio por la Hydro: nuevas inversioNES Y DESASTRES SOCIOAMBIENTALES EN BARCARENA.

La planta de aluminio, en el municipio de Barcarena, cercanías de Belém, y integrada ao Programa Carajás, fue construida en los años 1980, compuesto por el puerto (Vila do Conde), la hidroeléctrica de Tucurui, en el río Tocantins, y la logística de corredores de transporte terrestre y fluvial, con la bauxita traída de la Mineraçáo Rio do Norte, en el río Trombetas. La producción de energía es fundamental para el desarrollo de la cadena del aluminio, por ser una actividad industrial electro intensiva. Hay muchos países que poseen grandes reservas de bauxita, por ejemplo, sin, con todo, tener la misma "oferta" energética que Brasil dispone para la operacionalización de esa cadena. La implantación de las fábricas en Barcarena fue acompańada de un violento proceso de desplazamiento forzado de 
millares de familias.

El proceso de remoción de la población local fui mui violento. Para dar una formalidade legal se hizo con recursos normativos del Instituto de Terras do Pará (ITERPA), del Instituto de Colonização e Reforma Agrária (INCRA), de la Companhia de Desarrollo Industrial do Pará (CDI), y de la Companhia de Desenvolvimento de Barcarena (CODEBAR), portanto, diversas instituciones governamentales que funcionaram para viabilizar la explotación y non propriamente para promover el desarrollo social e económico. Tiene mas de 30 anos de resistencia de la popularicen local contra las praticas y las estratégias conduzidas por agentes empresariales para se apropriar de nuevos territorios, produciendo, a cada momento de expansión de la frontera del capital, nuevos desplazamientos forzados. Mas también pelos desastres ambientales y sociales que son denunciados hace décadas.

Recientemente hubo un grande desastres em Barcarena. Hubo el desbordamiento de piscinas de residuos, anunciado por los moradores de comunidades vecinas al emprendimiento de la Hydro, empresa noruega, se hizo público en febrero de 2018, y se constituye en el mayor desastre ambiental y social ocurrido en la Amazonia, con extrema contaminación de ríos y de todo el ecosistema de várzea, en la desembocadura del río Amazonas.

El parecer de los pesquisadores del Ministério de Salud confirmaram las denúncias de moradores que vivem en lás proximidades de la mineradora que transforma la bauxita en alumina para produzir el alumínio. Hubo un vazamiento de grandes proporciones de tóxicos de la minería, contendo soda cáustica. Contaminou los cursos de água, prejudicando áreas de trabajo, lugares de moradia e la salud de comunidades rurais y urbanas en Barcarena, Pará. La empresa es la gigante norueguesa Hydro. Criminosamente usou una "tabulación clandestina” para lançar efluentes no tratados, direto en los rios.

Embora negasse inicialmente su responsabilidad, la Hydro acabou por admitir, en una nota pública, la existência de uma tabulación que lanzaba una "lama contaminada". Esa tabulación fui descoberta por moradores e investigadores. Porém, después la Hydro 
passou a mobilizar recursos jurídicos y técnicos para niegar la existencia desses dutos, y no cumprir las responsabilidades legais frente a los desastres provocados. Las pressiones que vem de los movimentos sociais tem tido como respuesta amenizas de muertes y el clima es de tension, miedo y sofrimentos que se prolongam por mais de 30 ańos, desde la instalación desses empreendimentos ligados a la producción de commodities de alumínio, em lingotes, para la exportación ao mercado mundial.
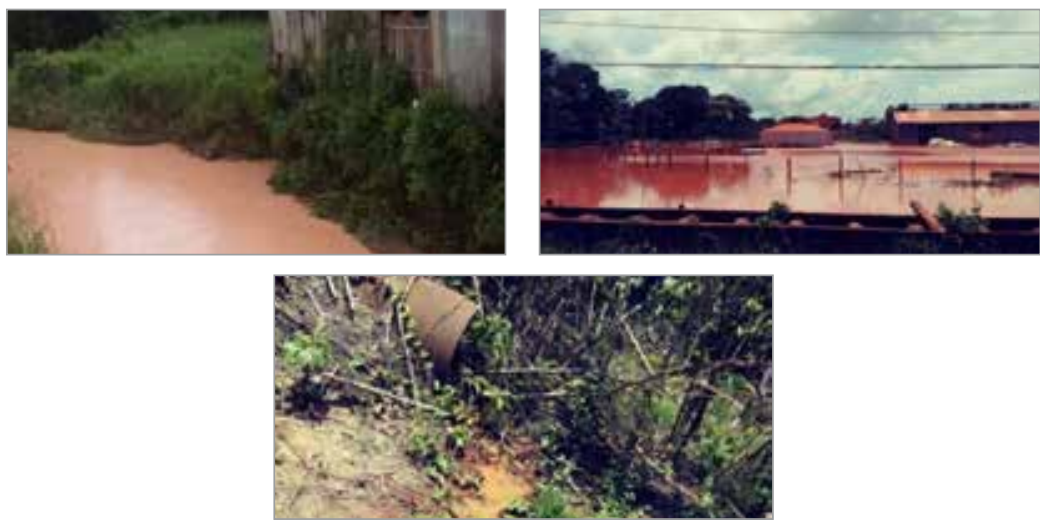

Figuras 5, 6 y 7 - El desbordamiento de piscinas de residuos en Barcarena, configura el mayor desastre ambiental y social ocurrido en la Amazonia.

6.3 El HierRo de La VALE: DUPLICACiÓN DE LA FERROVÍa; AMPLIACiÓN DE INSTALACIONES DE GASODUCTOS; AUMENTO DE LA EXTRACCIÓN DE HIERRO

La Vale do Rio Doce además de la explotación del hierro en la región de Carajás, inventarió, desde los años 1970, yacimientos de manganeso, níquel, casiterita, cobre y oro, todos allí localizados. En 1980, fue creado el Programa Grande Carajás (PGC), el cual objetivaba ser una área de planificación para la minería conjuntamente con otros proyectos de explotación de la floresta, de ganaderia, agricultura intensiva, que ya estaban en curso. Esta grande área atravessava los estados de Pará, Tocantins y Maranhão, correspondiendo a 10,52\% de todo el territorio brasileño. Una experiencia piloto de posesión de mega territorios por una área contigua que se extendía por 220 
municipios, la major parte en el estado del Pará. En la Estrada de Hierro que atravessa da mina, no Pará, hasta el puerto de Itaqui, em São Luis, en el Maranhão, com más de 900 kms, fueran instaladas diversas siderúrgicas de hierro-gusa, sobretodo em Marabá no Para, e Santa Inês y Açailandia, en Maranhão que utilizan hasta hoy el carbon vegetal, algunas ahora cerradas.

Un de los objetivos del Programa Grande Carajas era de industrializar una enorme extensión territorial a través de la minería, de usinas madereras y de expansión do agro-negocio, hoy lo que se observa es una región devastada, sin indústrias, con grande concentración de tierra, con los indices de cualidad de vida mui bajos. Ademas, la explotación intensiva de hierro, passadas quase 4 décadas, deja enormes áreas deforestadas y con crateras profundas alterando la paisagem y el territorio. La explotación de hierro en la región de Carajás aún tuvo graves implicaciones sobre diversos territorios indígenas localizados a lo largo de la extensión de la vía férrea, con problemas como la ausencia de la demarcación de tierras, invasión por parte de hacendados y otros actores sociales y apropiación y destrucción de los recursos de diversos territorios indígenas, como los Gavião Parkatejê, grupo timbira, cuyas tierras están localizadas en los alrededores de Marabá.
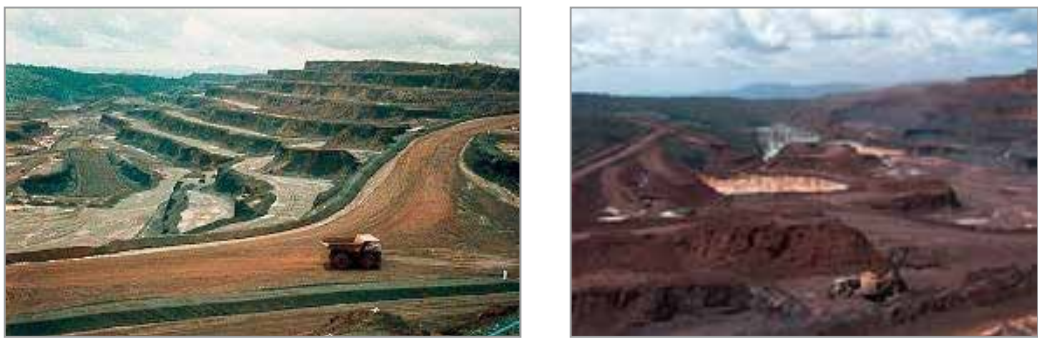

Figuras 8 y 9 - Explotación neoextrativista de hierro pela empresa Vale, en Carajás, en el estado del Pará.

El Instituto Socio Ambiental (2013) al elaborar un estudio sobre los conflictos de la minería, muestra que: 
"70 procesos incidentes sobre tierras indigenas "que têm 773.000 hectares delimitados, dos quais 496.373 hectares são alvo de interesses para extração de minério, representando 63\% do território indígena. Empresas como a Companhia Vale do Rio Doce, Samaúma Exportação e Importação Ltda., Joel de Souza Pinto, Mineração Capoeirana, Mineração Guariba e Mineração Nayara têm títulos minerários incidentes na Terra Indigena Apyterewa. Ainda tem muito mais. Independente das regras que norteiam o setor de mineração em vigor ainda hoje no Brasil, o governo pretende auto rizar a extraçáa de minérios - ouro $e$ diamantes, principalmente - em terras indigenas."

Los conflictos de tierra son persistentes, aunque diversos en cada uno de los casos examinados. En la época de realización de los estudios ambientales en el área donde fue construida la hidroeléctrica de Belo Monte, había innumerables conflictos instalados en tierras indígenas.

En sintiese, de los mega emprendimientos de minería que fueron iniciados en la Amazonia en la década de 1970, prácticamente todos poseían gran participación de presupuestos estatales brasileños, a través de la Companhia Vale do Rio Doce (CVRD). A lo largo de las décadas esos emprendimientos pasaron al sector privado, sobre todo a partir de la privatización de la empresa estatal Vale do Rio Doce.

\section{7.- Movimientos SOCiales, CONFlictos, ViolenCia y DeReChoS}

La cartografía de la violencia identifica la emergencia de innumerables casos relatados sobre las tres áreas de minería más importantes en Pará. Los estudios realizados permiten elaborar una interpretación de los derechos humanos y ambientales, identificando los efectos y daños de la minería en esos territorios, del sufrimiento, del desperdicio de vidas y de culturas e, igualmente, reflexionar sobre situaciones similares en países vecinos. Estudios en otros países latinoamericanos apuntan igualmente el crecimiento de la violencia como característica del neoextractivismo mineral a gran escala, asociándolos a conflictos sociales, pisco-sociales, étnicos y ambientales. Pero se identifica también esos territorios en la cartografía de la re- 
sistencia que viene siendo revelada por los movimientos sociales y luchas de grupos diversos.

La Amazonia brasileña está marcada por intensos conflictos ocurridos en las cuatro últimas décadas, justamente cuando hubo una expansión de la minería. Sobre ellos es posible recuperar los datos para montar una cartografía de la resistencia que envuelve diversos actores, todos conectados al territorio en la categoría de trabajadores de la tierra y de las aguas. Se trata de la resistencia de pueblos indígenas y de comunidades afro en la defensa de sus derechos constitucionales a la tierra; movimiento de los sin tierra por la reforma agraria ampliada; movimientos de los sin techo en las áreas urbanas; movimiento LGBT, de mujeres, de negros, pero también de trabajadores de las diversas empresas que componen el complejo de los mega emprendimientos. Son movimientos que tienen en su mayor parte un carácter territorial, pues responden a las amenazas de pérdida de derechos relacionados a la tierra e innegociables desde el punto de vista de la vida y de la cultura. Podemos denominar esas resistencias como un campo de acción política de naturaleza colectiva, inscrita en los grandes temas de la ecología política o de una gramática política. Hay, de hecho, un aumento extremo de la conflictividad socioambiental y, más recientemente, en todas las extensiones de la Amazonia invadida por grupos de fuera que llegan con capital y poder, orientadas por la perspectiva colonial que puede producir desplazamientos de personas, proyectos, culturas y saberes, para ocupar sus territorios. En esa resistencia a la instalación de emprendimientos mineros en la Amazonia, muchas masacres ya ocurrieron; muertes anunciadas de campesinos e indígenas, prisiones y desposesión de la tierra y de los derechos.

En ese modelo de territorialidad excluyente, resaltando que no son apenas los megaproyectos, las empresas se instituyen en actores que llegan a controlar la producción en el territorio en el cual se instalan. La vida dentro de los territorios ocupados por empresas mineras e hidroeléctricas pasa a ser un territorio conflagrado y, por eso, nacen otros conflictos en cuanto al derecho de uso de la tierra y de los recursos. Esa conflictividad sobrepone las fronteras del capital 
a las fronteras de derechos, como los derechos de los pueblos indígenas, garantizados por la Constitución brasileña de 1988 y también por dispositivos legales internacionales.

En cuanto al mapa de conflictos en América Latina, en áreas de minería tenemos también números impresionantes que muestran la violación de derechos sociales y su consecuente indignación. El mapeamiento exhaustivo de los conflictos divulgado por la CEPAL y del que participan Chile, Argentina y Colombia muestra el aumento de los conflictos de minería. En 2012 fueron 162 conflictos en el área de minería, siendo 212 comunidades afectadas. En 2014 ese número aumentó a 198 conflictos, afectando 296 comunidades en los referidos países.

Los movimientos sociales que vienen luchando por la defensa de derechos sociales, étnicos y ambientales, están articulados en redes mundiales para la defensa de los derechos. Ellos han manifestado las razones para controvertir esos emprendimientos, la naturaleza de las inversiones, los intereses en juego, los principales beneficiarios de los procesos de desterritorialización de poblaciones rurales, de territorios indígenas y afros; cabe señalar aún los desplazamiento forzados por las inundaciones o los cambios en la calidad de los recursos forestales y acuáticos, los obstáculos a las prácticas anteriores de movilidad por los ríos y, por eso, inviabilizando formas de trabajo de esas poblaciones. La contaminación puede ser identificada en varios aspectos: en la producción de gases y otros elementos químicos nocivos, en la filtración de sustancias contaminantes en los cursos de agua y en las tierras con agricultura, en la pérdida de peces y de la biodiversidad en general, entre otros. El concepto de "efectos derrame", como seńala Gudynas (2016), permite producir una alteración en la mirada, a partir de la observación de la complejidad que envuelve los impactos provocados por la gran minería en el territorio.

El discurso empresarial mantiene el eslogan del Brasil de los años 50: "somos una empresa de minería y no de desarrollo". Sin embargo, los impactos sociales y ambientales de la actividad productiva y de su crecimiento han sido socializados. Innumerables empresas han respondido con la producción de servicios dudosos de preservación 
y han irrespetado, sistemáticamente, los condicionantes sociales y ambientales exigidos por ley. En documentos oficiales ellas han señalado que la sobrevivencia de los emprendimientos de minería exige la flexibilización de reglas ambientales y derechos sociales, en función de la crisis económica y del escenario mundial de competitividad.

Las comunidades que viven en las áreas de ríos y de bosque en la Amazonia, muestran en el cuerpo las señales de la destrucción cuerpos marcados por heridas resultantes de la ingesta de minerales introducidos en la cadena alimentaria, sobre todo pescados; enfermedades respiratorias, dolencias derivadas del uso del agua y de la ingesta de frutos contaminados; desnutrición infantil; precarización de la vida en esos territorios. Por eso, es importante ver esos impactos, aparentemente "difusos", en sus múltiples desdoblamientos. Es el caso emblemático observado en la tragedia de Mariana, en Minas Gerais, en 2015 (ZHOURI, BOLADOS, CASTRO, 2016); desastres que resultan en situaciones completamente imprevisibles, como "derrame" (GUDYNAS, 2016) y la pertinencia de ese concepto desarrollado por Gudynas. Más recientemente, en febrero de 2018, hubo el desbordamiento de piscinas de desechos industriales de emprendimientos de bauxita y de aluminio, en el municipio de Barcarena, en el Estado de Pará, en la Amazonia, donde hace más de 30 años las comunidades se organizan y luchan contra la expansión de esos emprendimientos minerales sobre sus territorios. Diversas comunidades sufrieron más de dos desplazamientos forzados de su territorio; efectos siempre minimizados, desvalorizados, negados, en las narrativas de las empresas y del Estado, con el apoyo tácito de los grandes medios, que en Brasil están altamente comprometidos con la postura y las prácticas coloniales que atraviesan esos emprendimientos, toda vez que en el imaginario de segmentos de las elites nacionales la Amazonia debe ser una región pobre, vacía de saberes y competencias, y que el emprendimiento es el portador del progreso y del proceso civilizatorio. Esa mentalidad colonial es estructuralmente fuerte, impregnada en las capas sociales del país, define en gran parte la relación de poder entre regiones y torna "legítima" la 
apropiación de la tierra y de la vida - sociedades, cultura y naturaleza. Esa colonialidad incorporada y exteriorizada a través de prácticas autoritarias se torna un eje fundamental para entender el tránsito a los proyectos neoextractivistas y el saqueo intenso y continuo de los recursos naturales y de la vida organizada de áreas en la frontera del capital.

Muchos países en América Latina tienen una importante población viviendo en el campo y en pequeñas ciudades, con prácticas de agricultura familiar, pesca y recolección de una serie de productos creados en esa economía. El avance de la monocultura, sea con la producción de granos, de oleaginosas (el "dendê”), de plantaciones de eucalipto, significa también una extracción intensa y continua de recursos, de nutrientes del suelo hacia el agua y los lechos freáticos - por lo tanto, a nuestro modo de ver, se trata de procesos neoextractivistas y con la misma naturaleza de violencia sobre territorios ocupados por poblaciones tradicionales por la supresión de sus formas de vida, llevándolos a la marginalidad y a las periferias urbanas, violentas y con altos índices de desempleo. Eso ha ocurrido en Brasil, Colombia, Perú, Argentina, Chile, Paraguay y en muchos otros lugares de América Latina.

\section{Conclusión}

En lâs ultimas décadas observasse el crescimento en el mondo de movimentos sociais contra empreendimentos de minería, exemplo del Movimento de atingidos pela Mineração/MAM y el Movimento de atingidos por Barragens/MAB. En la Amazônia los impactos de la explotación minera tinem grande magnitude. Concentradores de grandes espacios geográficos, los proyectos de minería, en general, son causadores de múltiples problemas provenientes de su instalación en territorios ya efectivamente ocupados por poblaciones tradicionales. Su carácter contaminante y las formas de expropiación, en el caso de esos proyectos, han producido un campo de conflicto y violencia de amplia complejidad. Eso se puede dar con la inmediata instalación del proyecto o con el pasar de los años, caracterizando un 
avance lento y gradual de las violencias asociadas a la minería. Veremos algunos de esos problemas continuar en algunos de los principales proyectos de minería que se instalaron en la Amazonia a partir de la década de 1970.

Las tierras de la Amazonia han sido exhaustivamente observadas para identificar reservas de minerales. En los últimos ańos fueron identificados yacimientos de: bauxita, caolín, manganeso, oro, casiterita, cobre, níquel, niobio, uranio, en la región del río Xingu. En esa misma región fueron previstas, en el Plan Nacional del Sector Energético, la construcción de innumerables hidroeléctricas en Belo Monte, el Complejo Teles Pires y el Complejo Tapajós. No al azar, todas ellas tienen que ver con la producción de energía para el sector mineral, por tanto para explotación neoextractivista, con poco valor agregado.

Por otro lado, el interés por las tierras indígenas, ricas en minerales, no es nuevo, pero se ha intensificado, fundamentando demandas en el Congreso Nacional para desreglamentar los derechos de pueblos indígenas, reducción de áreas y flexibilización de procesos productivos altamente invasivos. Este es el caso de la región del Xingu que tiene yacimientos de oro, diamante, niobio, cobre, fósforo, fosfato, y su deslegitimación siempre fue un tema que circuló entre elites civiles y militares.

La expansión del capital sobre los diferentes biomas: de la selva, del cerrado, de la várzea y de los afluentes, los territorios de aguas, y las montańas. Al hablar de la dinámica de acumulación de capital que en estos momentos toma una rapidez impresionante, hay que consider la doble dinámica capitalista - no solamente explotación del trabajo, sino también el saqueo de la naturaleza -, donde el avance sobre la frontera es cada vez mayor en el mundo capitalista como muestra Wallerstein, 2014) Pero el proceso de acumulación no se discute hoy, como si esa realidad fuese del pasado. $\mathrm{Y}$, de hecho, desapareció, dando origen a otras narrativas sin sujetos y sin clases sociales, desplazando el conflicto, los movimientos insurgentes y la resistencia de sus lugares de clase. Un eje de narrativa que deja de lado la dinámica de acumulación y de la concentración del capital. 
La trayectoria de los grandes proyectos del sector de minería, por lo tanto, ha sido marcada por una relación colonial sobre los territorios ocupados, presuponiendo autoridad y hegemonía. El monopolio sobre la riqueza natural se hace acompańar del monopolio de la violencia política y simbólica.

El debate que viene siendo construido desde el final del siglo XX con fuerte participación de los movimientos sociales propone la institucionalización de un pensar jurídico que parta de la premisa de la naturaleza como sujeto de derecho, y el Estado garantizador de ese derecho, tanto como de los derechos humanos. En síntesis, pensar una sociedad bajo una distinta modalidad de integración con la naturaleza, apostando en conceptos como "buen vivir", como premisa de otro desarrollo. Tal perspectiva de la ecología política supone la institucionalización de una economía pos extractivista, sobre todo considerando el agotamiento de las reservas naturales y los crecientes eventos extremos vinculados a los procesos globales de cambio climático.

BiBLIOGRAFÍA

ACEVEDO Y CASTRO $(1992,1998)$ - Negros do Trombetas. Belém, CEJUP, 1992

ACOSTA, A. Extrativismo e neoextrativismo: Duas faces da mesma maldição In: Descolonizar o imeginário-Debates sobre o pós-extrativismo e alternativas ao desenvolvimento, 2016. p. 46-85,

ARAUJO, A. M. Todos los tiempos, el tiempo. Montevideo, Psicolivros, 2013

GUDYNAS, E.; ACOSTA, A. La renovación de la crítica al desarrollo y el buen vivir como alternativa. Utopía y Praxis Latinoamericana / Año 16. No 53 (Abril-Junio, 2011) Pp. 71 - 83 ADORNO, T.; HORKHEIMER, M. A dialética do esclarecimento. Rio de Janeiro: Zahar, 2005.

AGAMBEN, G. Homo Sacer: Estado de Exceção II. Trad. Iraci D. Poleti, São Paulo: Boitempo, 2004.

APPADURAI, A. Dimensóes culturais da globalização: a moder- 
nidade sem peias. Tradução de Telma Costa. Lisboa: Editorial Teorema LDA, 2004.

BANERJEE, S.B. Quem sustenta o desenvolvimento de quem?O desenvolvimento sustentável e a reinvenção da natureza. In: FERNANDES, M. ; GUERRA, L. (Orgs.). Contra-Discurso do Desenvolvimento Sustentável. Belém: UNAMAZ, 2006.

BAUMAN, Z. Vidas desperdiciadas. Buenos Aires, Ed. Paidós, 2006

BEBBINGTON, A. (ed.). Minería, movimientos sociales y respuestas campesinas. Lima, IEP y CEPES, 2007,

CASTELLS, M. A sociedade em rede. A era da informação: economia, sociedade e cultura. 3a. ed. Rio de Janeiro: Paz e Terra. 1999.

CASTRO, E., ALONSO, S. NASCIMENTO, S. Mineração na Pan-Amazônia: neoextrativismo, colonialidade e lutas territoriais. In: ZHOURY, A., BOLADOS, P., CASTRO, E. (orgs.). Mineração na América do Sul. Neoextrativismo e lutas territoriais. Belo Horizonte, Annablume, 2016

CASTRO, Edna - Campo do desenvolvimento, racionalidade, ciência e poder. In: FERNANDES, Ana Cristina; LACERDA, Norma; PONTUAL, Virgínia. - Desenvolvimento, planejamento e governança: o debate contemporâneo. Rio de Janeiro, Letra Capital, 2015, p. 225-246.

CASTRO, E. Pan-amazônia Refém? Expansão da Fronteira, Megaprojetos de Infraestrutura e integração sulamericana da IIRSA. In: FRANCO, F. (ed.). Megaproyectos: la amazonia en la encrucijada. Colombia: Universidad acional de Colombia. Sede Amazonia. Instituto Amazónico de Investigaciones - Imani, 2012a. pag. $177-216$

CASTRO, E. Expansão da fronteira, megaprojetos de infraestrutura e integração sul-americana. Caderno CRH, UFBA, v. 25, p. 45-62, $2012 b$.

CASTRO, E. Políticas de Estado e atores sociais na Amazônia contemporânea. In: BOLLE, W.; CASTRO, E.; VEJMELKA, M. (Orgs.). Amazônia - Região Universal e Teatro do Mundo. São 
Paulo; Belém: Globo, 2010. v. 1, p. 105-122.

ESCOBAR, A. El "postdesarrollo" como concepto y práctica social. In: MATO, D. (coord.). Políticas de economía, ambiente y sociedad en tiempos de globalización. Caracas: Universidad Central de Venezuela, 2005, p. 17-31

ESCOBAR, A. Actores, Redes e Novos Produtores de Conhecimento: os Movimentos Sociais e a Transição Paradigmática nas Ciências, in B.S. Santos (org.), Conhecimento Prudente para uma Vida Decente: Um Discurso Sobre as Ciências Revisitado. Porto: Afrontamento, 2003, p. 605-630.

FERNANDES, F. A integração do negro na sociedade de classes. São Paulo, Edusp, 1965.

GIDDENS, Anthony. As consequências da modernidade. 2 ed. São Paulo: UNESP, 1991.

GONDIM, N. A Invenção da Amazônia, Manaus, Série Memórias da Amazônia, Ed.Valer, 2a . Ed. 2007.

GUDYNAS, E.. La ecología política de la crisis global y los límites del capitalismo benévolo (Íconos, Revista de Ciencias Sociales, Quito, Flacso, n.36, p.53-67, 2010.

GUDYNAS, E. - Extractivismos en America del Sur: conceptos y sus efectos derrame.In: ZHOURY, A.; BOLADOS, P; CASTRO, E. (orgs.) Mineração na América do Sul. Neoextrativismo e lutas territoriais. Belo Horizonte, Annablume, 2016

HARBEMAS, J. Teoria de la accion comunicativa. Racionalidad de la accion y racionalizacion social. Buenos Aires: Taurus, 1989.

HARVEY, D. Roepke lecture in Economic Geography - crises, geographic disruptions and the uneven development of political responses. Economic Geography, v. 87, n. 1, p. 1-22, 2002

IANNI, O. Sociologia da Sociologia latino-americana. Rio de Janeiro: Civilização Brasileira, 1971.

ROLLA A. , RICARDO, F. - Mineração em Terras Indígenas na Amazônia Brasileira, São Paulo, IISA, 2013

LANDER, E. (org.) La Colonialidad del Saber: Eurocentrismo y Ciencias Sociales - perspectivas latinoamericanas. Buenos Aires: CLACSO, 2000a 
LANDER, E. "Eurocentrism and Colonialism in Latin American Social Thought", Nepantla: Views from South, 1(3), 519-532. CLACSO, Ciudad Autônoma de Buenos Aires, Argentina. setembro $2000 \mathrm{~b}$

LEFF, E. La ecología política en América Latina: un campo en construcción. Brasilia. Revista Sociedade e Estado, vol.18, no.1-2, p.17-40, 2003

LIPOVETSKY, G. O império do efêmero. São Paulo, Companhia de Bolso, 2009

LÖWY, M. Ecosocialism: towards a new civilization. Revista Novos Cadernos NAEA, Belém, vol.13, no. 1, p. 245-254, 2010.

MIGNOLO, W. Desobediência epistemológica. A opcao descolonial e o significado de identidade em política. Cadernos de Letras da UFF - Dossiê: Literatura, língua e identidade, no 34, p. 287-324, 2008

OLIVEIRA, F. de. Elegia para uma (re)Região. Rio de Janeiro, Ed. Zahar, 1996

QUIJANO, A. Colonialidade do poder, eurocentrismo e América Latina. In: LANDER, E. (coord.). A colonialidade do saber: eurocentrismo e ciências sociais - perspectivas latino-americanas. Buenos Aires: Clacso, 2005, p. 107

RAMOS, A. G. A redução sociológica. Rio de Janeiro: Ed. UFRJ, 1965.

RIST, G. Le development. Histoire d'une croyance occidentale. Paris, Presses de Sciences Po, 2001

RIVERA, C. S. Ch’ixinakax utxiwa. Una reflexión sobre prácticas y discursos descolonizadores. Buenos Aires: Tinta Limón, 2010.80 pp.

SALAMA, P. - La tourment en America Latina. Hacia donde van la economias de la region? Universidad de Guadalajara, El Colegio de la Frontera Norte. México, 2016a. http://libreria.colef. $\mathrm{mx} /$ detalle.aspx? $\mathrm{id}=7540$

SALAMA, P. Chine - Brésil: je t'aime, moi non plus. Revista Novos Cadernos NAEA, Belém, vol. 19, no. 1, p. 9-25, 2016 b.

SANTOS, B. de S. Para além do pensamento abissal: das linhas glo- 
bais à ecologia dos saberes. In: SANTOS, B. de S.; MENESES, M. P. G. (Orgs.). Epistemologias do Sul. Coimbra: Almedina; CES, 2009. P. 23-71.

SVAMPA, Margarete-Extrativismo neodesenvolvimentista e movimentos sociais Um giro ecoterritorial rumo a novas alternativas? In: DILGE, G.; LANG, M.; PEREIRA FILHO, J. (orgs.). Descolonizar o imaginário: Debates sobre pós-extrativismo e alternativas ao desenvolvimento, 2017

WALLERSTEIN, Immanuel - Impensar las ciencias sociales: Limites de los paradigmas decimonónicos. Siglo XXI de España Editores, S.A, 2004

ZHOURI , A.; VALENCIO, N. Formas de Matar, de morrer e de resistir. Limites da resolução negociada de conflitos ambientais. Belo Horizonte: editora da UFMG, 2014.

ZHOURI, A.; BOLADOS, P; CASTRO, E. (orgs.). Mineração na América do Sul. Neoextrativismo e lutas territoriais. Belo Horizonte, Annablume, 2016

Notas de PÁGina

${ }^{1}$ Más allá de las denuncias y movilizaciones de los movimientos sociales hace casi 30 ańos, sobre todo por la pérdida de sus territorios y la calidad del agua de los ríos y afluentes, en febrero de 2018 hubo filtración de desechos de bauxita, con el fango rojo invadiendo y alterando completamente la calidad de los cursos de agua, tornando el agua no potable, desapareciendo los pescados y contaminando un área enorme de tierras inundables, pues se trata de un ecosistema de várzea, de inundación estacional.

${ }^{2} \mathrm{Me}$ refiero aquí a autores que se dedicaron a entender los efectos de la especialización en la producción de bienes primarios en América Latina, sobre su desarrollo económico, las relaciones de intercambio en el sistema mundial y la desigualdad social. Entre otros, intelectuales fundamentales en el debate tales como Aníbal Quijano, Gunder Frank, José Mariátegui, Raul Prebisch, Theotônio dos 
Santos, Mauro Marine, Gino Germani, Florestan Fernandes, Silvia Rivera, Octavio Ianni y Guerreiro Ramos.

${ }^{3}$ La Ferrovía de Carajás atraviesa $830 \mathrm{~km}$ y es compuesta de 99 vagones con capacidad, cada uno, de transportar 80 toneladas de hierro, con una frecuencia de 2 convoyes al día.

${ }^{4}$ Los acontecimientos políticos recientes en Brasil iluminan el entendimiento de lo que es, de hecho, Brasil. Ellos revelaron la dureza de las relaciones coloniales y raciales que atraviesan el tejido social y se actualizan; una derecha y extrema derecha que apostaron todas las fichas en el impeachment de la Presidente Dilma Roussef para asentar en el poder los sectores más conservadores y comprometidos con el mercado, en un asalto rápido a la deconstrucción de derechos, del trabajo, de la pensión, de la pesquisa y la innovación tecnológica, una reducción severa del presupuesto para la educación y la salud públicas, liberalizando a economía e las instituciones, a favor de un movimiento en pro no solamente de la privatización de empresas y de activos públicos, mas también del agua, del suelo, del subsuelo - como se ha descubierto cada día en los acuerdos celebrados soterradamente. En el fondo, se puede observar que el neoextractivismo es una de las bases de las políticas del gobierno del Golpe y, entre los recursos naturales, el petróleo es el recurso de moda. Acuerdos coloniales subyacen a los decretos y medidas provisorias. Revela también la necesidad de más estudios sobre la mentalidad, las narrativas marcadas por una historia extractiva, del desperdicio, de la ignorancia del otro, que puede ser humano o no humano. Esa relación de alteridad deformada, al negar al otro, la destrucción de la condición de sujeto, sujeto de derechos, es la base ontológica, a nuestro modo de ver, de la constitución del "brasileño o, por lo menos, de ciertas capas configuradas en el descarte del otro, en la inviabilidad del otro $y$, por tanto, objeto de la reflexión del pensamiento crítico.

${ }^{5}$ En el sentido de la crítica formulada por Giddens (1991), Santos (2009) y Harvey (2002)

${ }^{6} \mathrm{~A}$ partir de las experiencias colectivas organizadas en torno del movimiento ecológico de los años 1960 y siguientes, se observó la continua ampliación del análisis crítico sobre las consecuencias so- 
ciales y ambientales de los procesos industriales, considerando sobre todo las amenazas al medio ambiente. Nuevas creencias y utopías son inventadas en torno del desarrollo. Se observó la profusión de imágenes y términos que accionan simbólicamente las ideas de sustentabilidad, seńalando utopías y creencias de nuestra época que, al mismo tiempo, positivan la noción de desarrollo. Es esencial el entendimiento del sistema de creencias de una sociedad, actualizado en cada época.

${ }^{7}$ Citamos, entre otros, Anibal Quijano, Gino Germani, Mauro Marinho, Guerreiro Ramos, Florestan Fernandes, Celso Furtado, Octavio Ianni, entre muchos otros, como muestra Lander (2000a, 2000b). En la misma dirección autores como Arturo Escobar (2003, 2005), Appadurai (2004), Banerjee (2006) y Santos (2009) entienden el discurso del desarrollo equivalente al de la construcción del otro en el discurso colonial.

${ }^{8}$ Pensar en el tiempo presente y en la radicalidad de la teoría crítica ha sido la provocación de ciertos autores sobre lo que ha sido llamado de hipermodernidad, como se puede ver en Araújo (2014).

${ }^{9} \mathrm{La}$ economía mundo, conforme observamos en Wallerstein (2014) y Salama (2016b).

${ }^{10} \mathrm{El}$ referido documento explicita que esos datos son referentes a: mineral de hierro y sus concentrados, excepto las piritas de hierro secadas al fuego (cenizas de piritas).

${ }^{11}$ Como vimos, la minería es una actividad económica que atraviesa los países latinoamericanos. En América del Sur se conforma una gran región conocida como Panamazonia que atraviesa las fronteras de 9 países (Brasil, Bolivia, Ecuador, Colombia, Guyana, Surinam, Guyana Francesa, Perú, Venezuela).

${ }^{12}$ En agosto de 2015 reunidos en Belo Horizonte, Estado de Minas Gerais, en el seminario Mineração na América Latina: Neoextratisvismo e lutas territoriais los participantes revisaron el sector extractivo mineral en América Latina, de los antiguos a los recientes emprendimientos, y cómo el sector es cada vez más regulado por la demanda de los mer-cados internacionales e impulsionado por gobiernos de todo el continente, sean conservadores o progresistas, 
produ-ciendo enormes impactos en la vida social, en el ambiente y en los patrones de ocupación de la tierra y de su ancestrali-dad.

${ }^{13}$ Los afroamericanos de Oriximiná y Cuminã ocupan nueve territorios étnicos en los márgenes de los ríos Trombetas, Erepecuru, Acapu y Cuminã, organizándose en más de 40 comunidades.

Fecha de Recepción del Artículo: 20 de marzo de 2018

Fecha de Aceptación: 1 de junio de 2018 